\title{
Designing and delivering representation-focused science lessons in a digital learning environment
}

\author{
Connie Cirkony ${ }^{1}$ (D) $\cdot$ Russell Tytler $^{2}$ (D) $\cdot$ Peter Hubber $^{2}$ (D)
}

Accepted: 3 February 2022 / Published online: 19 February 2022

(c) The Author(s) 2022

\begin{abstract}
Inquiry-based representation-focused approaches in science education have shown promising outcomes when students engage in knowledge building via an active process of constructing, coordinating, and evaluating representations. To date, much of the existing research around these approaches has taken place in pre-digital classrooms, but the increasing importance of digital technologies in contemporary science classrooms that has heightened during the on-going Covid pandemic could have ramifications for such approaches. To explore the potential for productive integration of a digital technology with active learning processes, this study investigated the role an interactive online learning platform played in supporting the construction and refinement of representations by students. This paper draws on research generated in the context of an Australian Grade 9 science class studying a physics unit focused on energy transfer considerations for sustainable housing. The research design featured an exploratory case study approach using multiple methods for data collection including video capture, interviews, and student artefacts. Data analysis involved the application of socio-semiotic perspectives to understand the nature of students' meaning-making processes through their generation and coordination of both digital and non-digital multimodal representations. This study found that the online platform allowed for extended access and the flexible use of multimodal resources facilitated students' representation construction activities. However, activities involving teacher-guided discussions and ongoing feedback were limited. The socio-semiotic analysis provided insights into the effective design of online learning sequences to guide conceptual development. This paper concludes by suggesting how specific affordances of interactive online platforms can effectively facilitate the design and delivery of active learning approaches involving representation construction.
\end{abstract}

Keywords Online learning platform · Science education · Inquiry-based learning · Representations · Conceptual development

Connie Cirkony

connie.cirkony@monash.edu

Extended author information available on the last page of the article 


\section{Introduction}

Multimodal representations, such as symbols, graphs, and images, have a long history in science (Latour, 1990) and they are fundamental tools through which thinking and knowing in science occurs (e.g., Ainsworth et al., 2011; Airey \& Linder, 2009; diSessa, 2004). Thus, learning how to interpret information and communicate thinking with multimodal representations is a fundamental aspect of science education (Lemke, 2004) and central to the development of core disciplinary literacy in science (Tang \& Danielsson, 2018). In science classrooms, pedagogical approaches focused on these representations have demonstrated promising outcomes for student learning (Lehrer \& Schauble, 2006; Tytler et al., 2013). As a culmination of these practices, the Representation Construction Approach (RCA) has gained empirical evidence as a pedagogy that involves students constructing, evaluating, and coordinating representations to make sense of concepts and solve problems (Knain et al., 2021; Tang et al., 2019; Waldrip et al., 2013; Xu et al., 2021).

In the RCA, teachers use guided inquiry to facilitate discussions and activities around representations generated by students, build class consensus, and guide students toward scientific understanding. Students experience knowledge construction through the creative and collaborative processes of refining ideas and evaluating their own claims and those of others. In doing so, students become more engaged in their own learning (Ainsworth et al., 2011), develop disciplinary literacies of science (Tang \& Danielsson, 2018), build representational competence (Daniel et al., 2018; diSessa, 2004; Kozma \& Russell, 2005; $\mathrm{Xu}$ et al., 2021) and achieve a deeper understanding of fundamental concepts (Lehrer \& Schauble, 2006). Building on students' "deep, rich, and generative" understanding of representations (diSessa \& Sherin, 2000, p. 387) and having them construct their own representations provides powerful affordances for learning (Ainsworth et al., 2011).

Most research into RCA has taken place in pre-digital classrooms, involving ongoing researcher guidance for implementation (e.g., Lehrer \& Schauble, 2006; Tytler et al., 2013). However, using online learning platforms, digital technologies are increasingly commonplace in classrooms (Martin et al., 2020), and the rapid shift to online learning during the pandemic has highlighted their importance (An et al., 2021). While initially used to organise and deliver static content and closed tasks, with often mixed learning improvements (Barbour, 2014), in recent times online platforms have supported more varied and collaborative pedagogies, activities, and assessment (Richards \& Dede, 2012). Increasingly, online designs incorporate open and active-learning pedagogies such as inquiry, problem- and project-based learning (Freeman et al., 2017), and adaptive learning technologies (Martin et al., 2020; Wu \& Wang, 2016), with the potential to scale up these interactive approaches.

When applied to school science, Longo (2016) suggested that inquiry-based blended learning approaches increased student motivation, creativity, critical thinking, and were more reflective of the epistemic practices of scientific thinking. One earlier design, the widely adopted Web-based Inquiry Science Environment (WISE), is a flexible authoring environment that incorporates digital scaffolds and tools to facilitate inquiry approaches for secondary school science. Its platform allows teachers to embed prompts (e.g., hints) and resources (e.g., simulations, drawing tools) within a structured learning sequence (Slotta \& Linn, 2009).

Other adaptive web-based learning environments have since incorporated open and interactive pedagogies (e.g., inquiry) in their design, resulting in more personalised science learning experiences through algorithms customised to students' learning progressions and preferences (Panjaburee \& Srisawasdi, 2016; She \& Liao, 2010). Although the quality 
of learning associated with exclusive online learning is mixed (Barbour, 2014; Means et al., 2009), classroom settings where teachers blend face-to-face and online interactions show more promising outcomes (She \& Liao, 2010; Slotta \& Linn, 2009). These teacherfacilitated approaches are also thought to be a more appropriate choice for K-12 learners who require greater guidance (Longo, 2016; Means et al., 2009). To date, however, there has been little research into platforms' ability to support students in the generative processes associated with RCA. Therefore, this paper explores new ground by investigating the potential of an online learning platform for facilitating the interactive, multimodal processes that are central to the generative pedagogy of the RCA.

The online learning platform under investigation is the Student Teacher Interactive Learning Environment (STILE), designed by an Australian company specialising in cloudbased teaching and learning software to support science units in K-12 classrooms. STILE is an example of a customisable interactive platform with the kinds of collaborative functions proposed by Richards and Dede (2012). It can also support open-ended multimedia and multimodal approaches to teaching and learning and is freely available to government secondary schools (Victoria Department of Education, 2020). Using this platform, the research team worked with a group of Grade 9 teachers to create a customised science unit, incorporating RCA pedagogy (see below), which was implemented by the teachers in their science classrooms through a combination of online and face-to-face interactions. The design reflected the theoretical underpinnings of RCA, as described in the following section.

\section{Theoretical underpinnings of the representation construction approach}

RCA is informed by socio-semiotics, emphasising language as the basis of the formal and informal reasoning processes that underpin cognition (Bezemer \& Kress, 2016; Tytler \& Prain, 2010). The socio-semiotic perspective focuses on the use of signs (e.g., words, pictures, gestures) to convey and interpret meaning for making sense of the world within a given social and cultural context (Peirce, 1998). Expanding on these ideas, socio-semiotic theory considers meaning to be distributed across different representational forms (e.g., dialogue, written text, drawings, graphs, role-plays) and modes (i.e., verbal, written, visual, action) (Bezemer \& Kress, 2016), each of which offers partial access to meaning. The possibilities for meaning making are thus contingent on the range of representations and modes, and the tools and activities available to generate and integrate them in a learning environment (Kress, 2010). Thus, the notion of generative features emerges from the sociosemiotic and epistemic theoretical perspectives which underpin RCA. The term refers to dynamic processes used to construct meaning and plans of action (Wittrock, 1992), and in this research setting such generative features are embedded in the unit design and delivery to facilitate meaning-making processes.

In RCA, students learn through constructing, coordinating, and refining their own representational resources in a teacher-guided communal process (Tytler \& Prain, 2010). This approach is consistent with social constructivist perspectives that propose authentic learning takes place as teachers and students co-construct knowledge through discipline-based languages and practices to develop, justify, and communicate meaning (Waldrip et al., 2013; Xu et al., 2021). For example, in the discipline of science, meaning making occurs through activities that integrate text, dialogue, mathematical formulas, visual representations, and apparatus (Lemke, 2004). Concepts are not static facts or written definitions, but 
linked ideas and practices within a disciplinary context (Taber, 2013) that constitute the sum of the representations that describe them (Lemke, 1998).

RCA as a pedagogy has distinct features, aspects of which are highlighted below (in italics) as a forerunner to the development of an analytical framework for this study (see Research Design section below). First, in RCA students are not initially provided with scientifically acceptable, or expert-generated representations of knowledge; rather students construct and coordinate their own representations to explain phenomena, make claims and negotiate meaning as they are challenged and guided by the teacher and/or their peers. Learning occurs as students translate meaning across representational forms and modes, that is, as 'cross modal translation' and through associated activities and conversations (Waldrip et al., 2013). As they focus on the features of their representations that enable or constrain meaning in different modes (i.e., modal affordances), students develop deeper conceptual understanding (Ainsworth, 2006; Prain \& Tytler, 2012). Drawing on Gibson's (1979) affordance theory, affordances are specific features of an environment that prompt or support an action. The term 'modal affordance' when applied to RCA refers to how well a given mode enables or constrains the expression of meaning, for example, written text versus an annotated diagram. Thus, some authors perceive each mode affords a 'productive constraint' for the expression of conceptual ideas (Ainsworth, 2006; Daniel et al., 2018; Knain et al., 2021; Prain \& Tytler, 2012; Tang et al., 2019).

Second, RCA pedagogy emphasises teacher-guided inquiry and collaborative discussions around student-generated representations for evaluation and refinement (Hubber et al., 2010; Tytler \& Prain, 2010). These interactions can be realised through a series of representational challenges, which are open-ended, iterative, and conceptually focused tasks (Tytler et al., 2013; Wilson \& Bradbury, 2021). Each task must be meaningful to students and require a response through exploration and representation in a specific modal form (e.g., drawing, role-play). The introduction of each representational challenge requires the teacher to first elicit students' ideas and seed possibilities to help students focus on what is important to notice and represent (e.g., why does warm air rise and how can we represent this though gestures or drawing?). Through the sharing and evaluation of their representations, teachers identify and evaluate students' ideas, including those that are inconsistent with the accepted scientific ones.

Third, based on students' responses, the teacher continues with relevant activities and facilitates class discussion of students' representations to identify and discuss the form and function of the more productive examples. These interactions help the teacher to identify and facilitate students' emerging conceptual understandings and representational competence and enable adaptation of activities and questioning to address the adequacy of students' claims in relation to their use of a range representational forms (Kenny \& Cirkony, in review). Fourth, in doing so, the teacher scaffolds the building of a consensus view, and may provide further resources and explanations (e.g., scientific diagrams or video, expertgenerated models) to help students gradually revise and align their representations more with the accepted scientific ideas and practices. Finally, students are challenged to apply their developing knowledge to explain phenomena in a new context.

\section{Aim, theoretical framework, and research questions}

This paper draws on findings from a study concerned with how Grade 9 Australian science students responded to an online unit on energy transfer, designed using the RCA. A detailed and exploratory case study of the design and implementation of two STILE-based 
lessons from the unit was undertaken, and this article reports on the extent to which the online learning platform facilitated students' representational work and learning as a component of RCA in a science classroom.

The analysis focused on the provision and coordination of multimodal representations and activities (e.g., social interactions, resources) and the possibilities for meaning-making (Kress, 2010) through student-generated representations. Based on the four key and distinguishing generative features of the RCA pedagogy (see earlier on pp. 5-6), an analytical framework was developed for assessing the potential of this online platform. Guided by a socio-semiotic perspective, this framework therefore focuses on the ways in which the platform facilitated: students constructing a range of representational forms and modes; implementation of the representational challenges designed to promote students conceptual and representational development; the coordination of students' representations with scientific ideas; and teacher-guided discussions and activities to iteratively develop students' scientific understandings in different contexts.

With these considerations in mind, the following analytical framework was designed (in the form of performance criteria) and applied to the data to evaluate the ability of the online learning platform to facilitate the learning processes in RCA. Thus an effective platform:

1. Enables students to construct and coordinate representations;

2. Provides evidence of student growth in representational competence and conceptual understanding;

3. Enables the progressive alignment of student constructed representations with scientific ideas, and moves students towards scientifically valid representational practices

4. Enables teacher-guided collaborative discussions and evaluation around student-generated representations.

These analyses were used to address two research questions:

1. What are the affordances and/or constraints of the online learning platform Student Teacher Interactive Learning Environment (STILE) when used to facilitate the central learning processes of the Representation Construction Approach (RCA)?

2. What are the key considerations in designing and delivering representation-focused learning sequences online?

\section{Research design}

The 3-month investigation was undertaken at a secondary, all-girls, Catholic school in Melbourne, Australia (Cirkony, 2019). The school offers courses and programs from Grades 7-12, including the Middle Years Programme (MYP) in the International Baccalaureate Organisation for Grades 7-10. The research design followed a video-based ethnography, with a case study approach, of a general science class studying a physics unit about energy transfer. The participants included 27 Grade 9 students and their teacher.

The ethnography involved the researcher (i.e., first author) situating herself in the classroom as a participant-observer and observing the rules and behaviours of the school and classroom to minimise disruption (Jupp, 2006). To answer calls to understand how students 
incorporate features across representational modes as they develop conceptual knowledge (e.g., Airey \& Linder, 2009), three GoPro ${ }^{\mathrm{TM}}$ video cameras were also used in the classroom to achieve a more in-depth investigation of learning processes that occur through conversation, gestures, interactions, and actions in context (Cohen et al., 2013; Yin, 2014).

This case-study approach also provided a practical method for complexity reduction and a fine-grained data analysis (Klette, 2009). Data collection commenced at the beginning of the unit, and comprised observations of participants, field notes, video capture of a case study group of three students, and their test responses, along with digital and analogic artefacts. The first author was present throughout to manage the video capture, undertake observations, and assist with the technology-and on one occasion, to witness the teaching as a participant observer (Pink, 2007). The use of multiple methods was to enable an understanding through multiple perspectives, experiences, and interpretations in context (Jupp, 2006; Pink, 2007).

Throughout the unit, students worked in similar groups. This article focused on a case group of three students, Jessica, McKinley, and Clara, for an in-depth exploration of their interactions during the module (Flyvbjerg, 2006; Yin, 2014). This group was chosen on the basis that they worked together consistently throughout the unit and compared to other groups, they presented the most comprehensive data set and demonstrated the strongest capacity to verbalise their reasoning with one another (Furberg et al., 2013). This group also demonstrated one of the biggest learning gains, with initial pre-test results below the class average. The unique nature of case studies means that while the reported findings cannot be generalisable (Cohen et al., 2013; Jupp, 2006), they can add insights into existing theories (i.e., representation-focused approaches in a digital learning environment), along with new ways of thinking that may lead to educational change (Cohen et al., 2013; Yin, 2014).

The setting was a face-to-face science classroom with desks and chairs arranged for six groups of four to six students, along with a formal laboratory work area. The online learning platform was accessed by students using their individual laptops, which featured a removable keyboard, Active-Pen ${ }^{\mathrm{TM}}$ technology, and a built-in camera.

\section{Unit design and implementation}

The unit content focused on forms, transformation, and transfer of energy, following the prescribed national curriculum (Australian Curriculum, Assessment and Reporting Authority [ACARA], 2018, ACSSU182). Using the context of sustainable housing, the unit was designed primarily by the third author (to incorporate RCA principles and adapt it for use with the online STILE platform) with input from the first author and the Grade 9 science teaching team. The Grade 9 teaching team were experienced science teachers, who had received two years of professional development in RCA along with previous experience of implementing this approach in their respective classrooms. This research project was the first time these teachers implemented the unit, as a classroom-based learning experience integrating both face-to-face and online interactions through the STILE platform. The unit contained a sequence of 12 modules made available on STILE (each taking 60- to 90-min over a single lesson) and a pre- and post-test, along with a summative inquiry-based task. Students were also provided with individual project books containing both lined and unlined pages to accommodate text and drawings.

The modules incorporated digital features specific to the online platform, including embedded multimedia resources (e.g., digital images, videos, simulations) and assessments 
with both multiple-choice and true-false questions and customisable automated feedback. The platform was also a repository for students' work, allowing them to respond directly to questions embedded in the module or to upload their responses from their project books. Two further applications also enabled open-ended responses: the interactive canvas allowed students to draw and annotate diagrams and integrate multiple media; and the written response application provided an infinitely expanded ruled pad allowing students to construct text-based responses.

Initial modules focused on establishing the context of climate change and sustainable housing, with subsequent modules following specific conceptual foci relating to energy transfer. Each module included multimodal activities to elicit students' prior knowledge and allow them to iteratively create and revise representations of their ideas (i.e., re-represent) in different contexts. The teacher had access to students' responses for the purpose of discussion and refinement of their scientific understanding.

Given the difficulty in reporting a full analysis of such a lengthy and complex sequence, this article focuses on two specific modules, selected to illustrate differences in design and learning outcomes. Each focused on specific concepts regarding heat transfer using the particle model of matter (ACARA, 2018). The first module introduced particle ideas to explain temperature and transfer of thermal energy through conduction. The second module focused on convection. Appendix 1 provides a synopsis of these modules with a description of the lesson and activities as planned on the platform.

\section{The temperature and thermal energy module}

The first module focused on energy transfer, and was followed by three others on conduction, convection, and radiation respectively. The purpose of the first module was to introduce students to the role the particle model can play in explaining temperature, thermal energy, and heat transfer. The following conceptual foci were presented on the first page of the online module:

- The temperature of an object is related to the average kinetic energy of the particles that make up the object.

- The thermal energy of an object relates to the total kinetic energy (movement) and of the particles that make up the object.

- Heat is the energy that gets transferred from hot objects to cooler objects.

This module consisted of five activities embedded in the platform (see Activities 5.1-5.5 in Appendix 1).

\section{The convection module}

Students spent the subsequent lesson learning about conduction, before undertaking the convection module, with the following conceptual focus:

- Energy can be transferred from one system to another (or from a system to its environment) in different ways: by conduction, convection, or radiation (electromagnetic waves).

- Convection is the transfer of energy between an object and its environment, due to fluid motion either in a gas or liquid. 
This module consisted of two activities embedded in the platform (see Activities 7.1-7.2 in Appendix 1), along with an additional teacher-led demonstration.

\section{Analysis}

To enable an in-depth tracking of students' engagement with representation construction processes, the analytical framework was applied to selected representations from the case group of three students. This framework enabled an interpretive approach to the evaluation of students' responses, drawing on socio-semiotic perspectives and students' conceptual development in relation to the scientific ideas as outlined in the school curriculum. Given that no single representation can fully convey conceptual meaning (Lemke, 1998), and there is no ideal representation (diSessa, 2004), this approach provided a theoretically informed and practical way to assess the variation presented in students' representations. Like other small-scale studies (e.g., Hubber et al., 2010; Waldrip et al., 2013), this study drew on qualitative interpretation to determine to what degree students' responses were consistent with scientific ideas, and, where possible, corroborated with observations and interviews. The unit of analysis is the module, as it reflects the sequencing of the representational challenges to facilitate students' conceptual and representational development.

As an interpretive analysis, trustworthiness was established through several activities associated with the investigation itself, as well as the analysis for this article. Firstly, in this ethnography, the primary author, as a participant observer, attended most lessons in the unit, which helped to build trust with other participants and better understand their learning experiences (Pink, 2007). The credibility of the data was supported using multiple sources and methods of data collection (e.g., observations, video-capture, interviews, document analysis) and their triangulation for depth of understanding, thereby emphasising the students' perspectives (Cohen et al., 2013). The credibility of the analysis was supported through thick descriptions of the context and participants' perspectives, with claims supported through the integration of data (i.e., drawings, observations, interviews). Finally, all three authors had expertise in the research in and conduct of RCA and discussed the findings extensively, including the evaluation of the multimodal representations through socio-semiotic theory, during the investigation and the development of this article.

\section{Findings}

The findings are presented under headings related to the four focus areas of the analytical framework as outlined in the Methodology section above, drawing on the data generated in the two modules, Temperature and Thermal Energy and Convection.

\section{Constructing and coordinating representations}

The students constructed and coordinated representations in both modules, in their project books and the interactive canvas (e.g., see Figs. 1, 2, 4, 5, 6, 8). For the first open-ended representational challenges (Activity 5.2), all three students in the case group chose to use the online interactive canvas for this task. The case group generated a variety of drawings using the paint tools of the interactive canvas (e.g., pen, shapes, lines, text, image, colour) accessible through their laptop cursor and trackpad. Each response was unique, although 
Fig. 1 Jessica's response to the six representational challenges
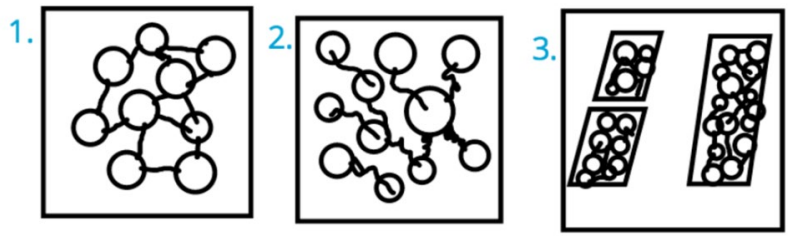

4.

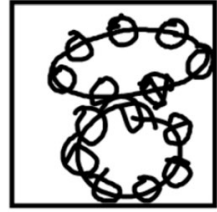

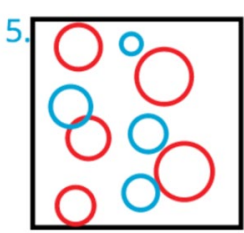

all 6 boxes, representing questions 1.5

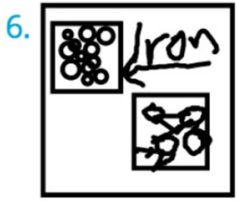

some similarities in their representations were noted (e.g., colour, annotations). Figure 1 is an example of a students' response to the six representational challenges.

For the first two scenarios (i.e., 1. plasticine lump holding its shape and 2. plasticine lump with a shape change) to reflect scientific understanding each diagram needed to depict the connectedness of the particles, but in scenario 2 the students needed to show that while the inter-particle bonds remain intact the arrangement of particles changed. All three students depicted particles and connectedness, and their re-arrangement. For the third scenario, the diagrams needed to depict a fragility or weakness of the bonds to explain the brittle nature of the piece of chalk. Clara added bolded text to her drawing while Jessica and McKinley drew an actual break. For the fourth, the particles of the stretching rubber band should have remained unchanged while only the bonds stretched. Jessica and McKinley were able to depict these ideas. For the fifth, when red cordial and water are mixed, students needed to show the intermingling of the water and cordial particles. All three students illustrated these ideas, with Jessica and Clara adding colour and McKinley using arrows to show the displacement of particles. Finally, for the sixth scenario where differences in the heaviness of iron and aluminium were to be explained, students needed to show either more or larger particles to explain a difference. All students generated a pair of diagrams, with Jessica and McKinley coordinating diagrams and text through annotations.

Students also generated dynamic representations during the Temperature Role-Play (plasticine lump maintaining its shape at two different temperatures, 20 degrees apart) and reflection (Activity 5.3). In the classroom, the case group created a role-play with three other students accompanied by ongoing discussion amongst themselves about how to do the activity. Individually, they wrote their reflections using the written response application on the platform. They indicated their understanding of particle connectedness through linked arms, with movement and bouncing taking place only in the second scenario. Jessica's written response was indicative of her group's ideas:

For the first challenge we (as particles) stayed still and linked our arms to show that our bonds were connected to show that we were still a lump of plasticine. For the second challenge we stayed linked together, but bounced and moved around, to show the plasticine being heated to 20 degrees.

In both the role-play and written representations, students exhibited only a partial understanding of particle ideas in solids by assuming no movement at lower temperatures. 
In the Convection module, students also generated an open-ended representation in response to the hands-on activity (i.e., Activity 7.2 involving convection currents in a teabag rocket). Prior to undertaking the activity students viewed a video, and as it was playing the teacher prompted students to think about what was going on inside the teabag when it was moving upwards: "You need to think about: Is there a fluid inside that bag? What's happening with the convection current and why is it going up?" Students did the task in their groups, and then responded to the final question in the online module asking them to explain why the tea-bag ash rose up in the air using their understanding of energy transfer (see Appendix 1). However, issues with internet connectivity in this lesson meant students responded in their project books (see Fig. 2). As students were working, the teacher prompted them with questions: "What fluid is inside the teabag tube? What is heating going to do to that fluid? How can you draw that convection current? And why then, is that rocket rising in the air?" Jessica and McKinley uploaded their responses to the platform, and Clara did not provide a response (see Fig. 2).

Both Jessica and McKinley combined visual and textual modes in their responses to explain the convection currents in the teabag rocket, in relation to the heat. They applied the same arrow conventions they used in Activity 7.1, but the colour and direction of arrows were consistent with the scientific views.

\section{Student growth in representational competence and conceptual understanding}

Student growth in representational competence and conceptual understanding was demonstrated through the activities in the first module. Activity 5.1 (a true and false survey to assess students' prior knowledge) showed the average score for the class was $41 \%$. Members in the case group scored an average of $28.5 \%$ (though their responses were not necessarily the same), which suggested their understanding of basic ideas about the particle model was limited. In comparison, $77 \%$ of the class responding correctly to ideas related to the conservation of matter (i.e., Q4); whereas, $81 \%$ of the students responded incorrectly to $\mathrm{Q} 1$, which stated all freezing substances must be below $0{ }^{\circ} \mathrm{C}$.

The following two activities enabled students to express their ideas across different representations. In their drawings (Activity 5.2) and role-play (Activity 5.3), the case study students consistently represented solid particles as stationary, a common alternative conception to the scientific idea that was consistent with their Activity 5.1 survey responses.

This first video-based scientific explanation was depicted in Activity 5.4 as a short animation demonstrating particles and movement (see Fig. 3).

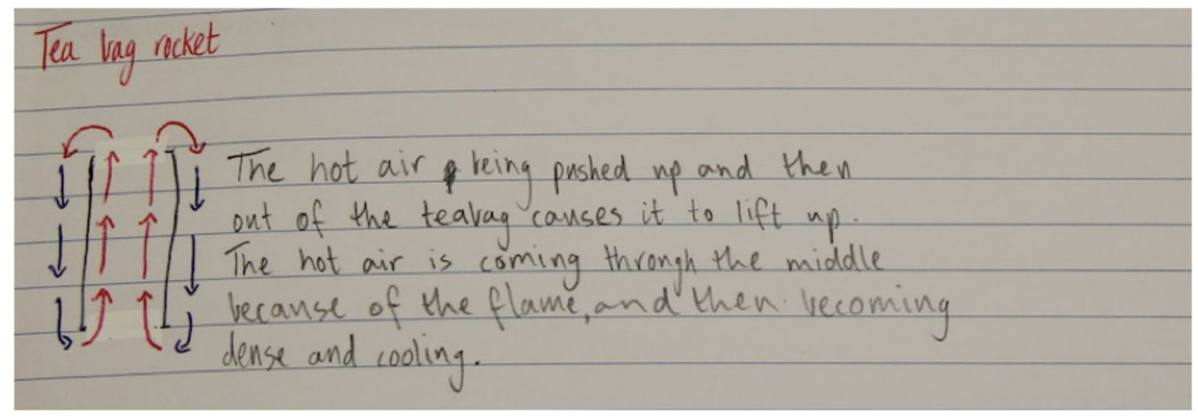

Fig. 2 McKinley's teabag rocket representations 

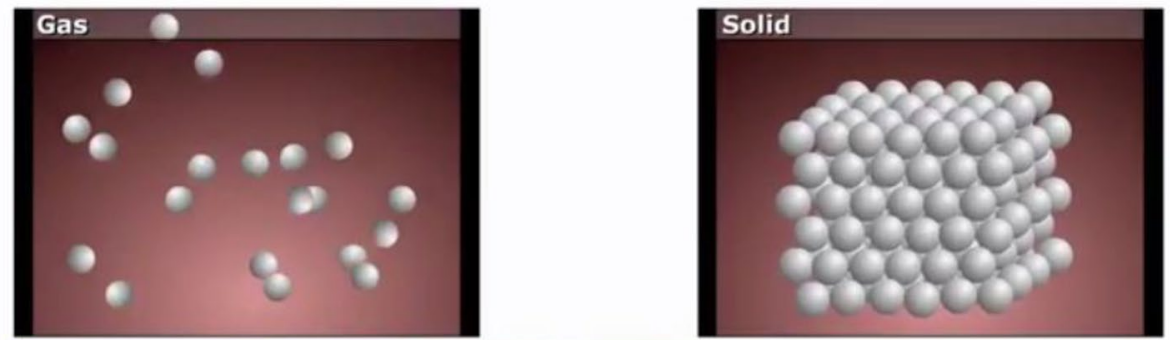

Study each of these animations
that show particles moving in
each of the states of matter.
How would you describe how a
typical particle moves in each of
the states?

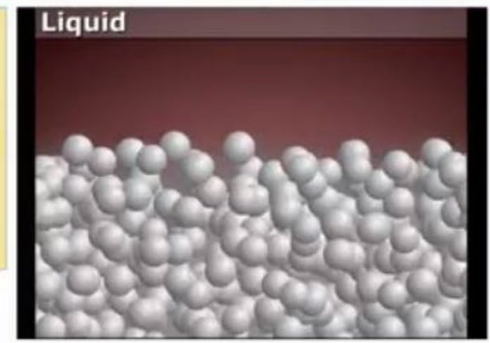

Fig. 3 Screenshot of the animation of 'particles in motion' in Activity 5.4. Adapted from "Royal Society of Chemistry and Science Enhancement Programme" [CD ROM], by P. Hollamby, 2006. Royal Society of Chemistry

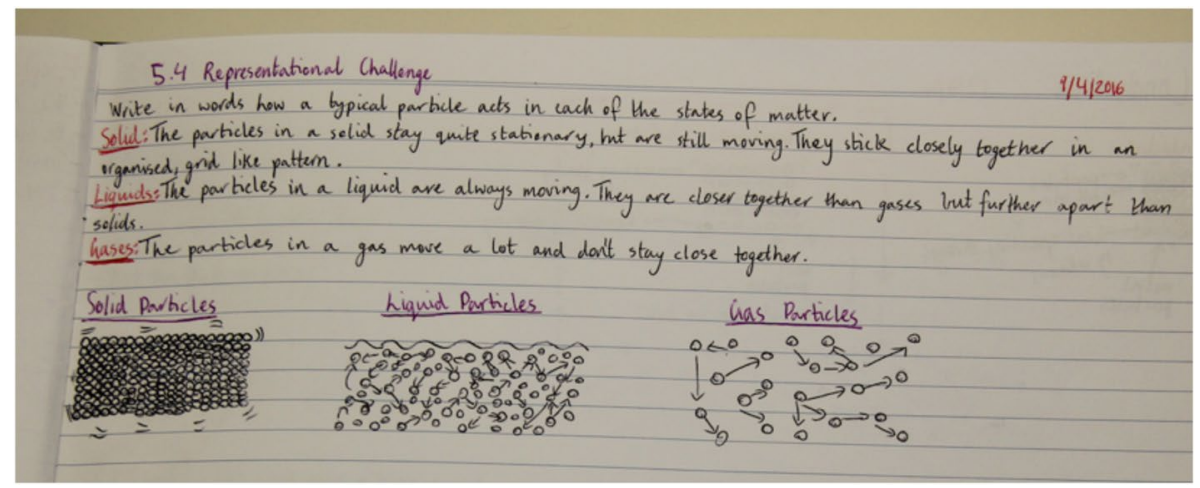

Fig. 4 McKinley's response to representational challenge 5.4

Jessica provided a written response only, whereas McKinley and Clara provided both written explanations and diagrams through hand-written and digital means respectively (see McKinley's response in Fig. 4).

In response to the question presented in the video, students re-represented their ideas about matter using digital or hand-drawn diagrams and text to integrate their ideas about particle movement (see Clara's response in Fig. 5).

All three case-study students were able to express the idea of spatial proximity and motion of particles for all three states through both text and diagrams, signifying a shift from their ideas about solids as stationary. 


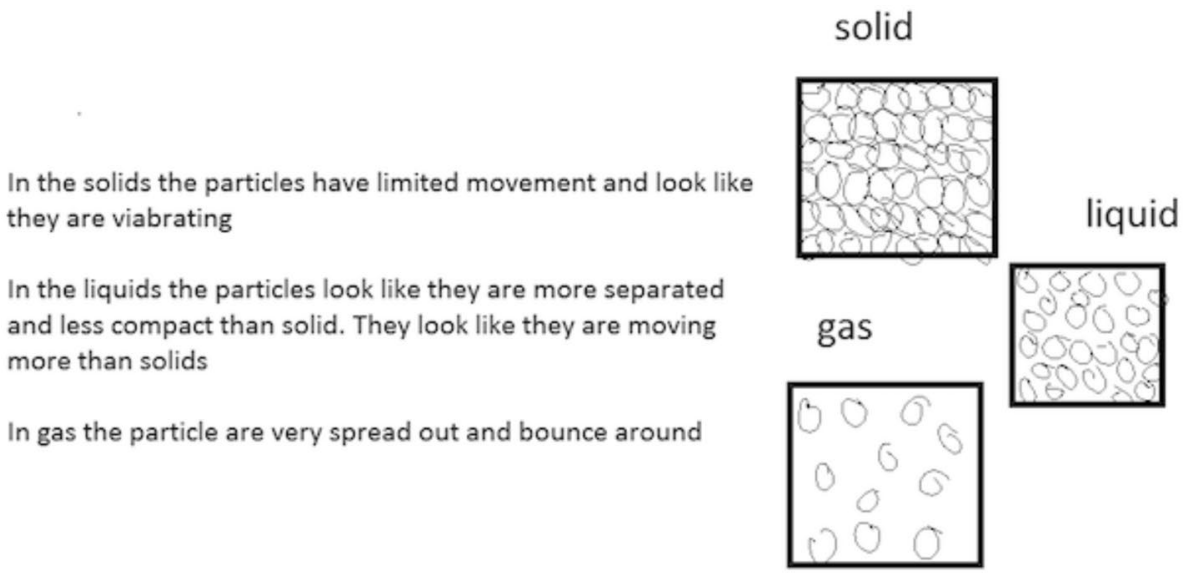

Fig. 5 Clara's response to representational challenge 5.4

As the final activity in this sequence, students were required to transfer their ideas to new contexts (Activity 5.5). Responding directly in the platform, Jessica and McKinley constructed annotated diagrams and Clara provided a written response (see Jessica's response in Fig. 6).

This first task revisited how particles change their vibration rate in a solid where the temperature is changing sufficiently to require changes in inter-molecular bonds. This task required students to translate scientific ideas into $2 \mathrm{D}$ representations. In response, all three students indicated change in particle movement through text and diagrams, demonstrating a consistent shift in understanding of particle motion in solids. Jessica and McKinley related their text to their diagrams, indicating their increased sophistication in representing their ideas. Clara chose to respond using digital text: "The piece of chocolate that is 10 degrees will have less kinetic energy and have less movement but the other chocolate piece which is 20 degrees will have more kinetic energy." Her explanation indicated an uptake of scientific ideas presented in the video.

Fig. 6 Jessica's representations of chocolate at $10^{\circ} \mathrm{C}$ and $20^{\circ} \mathrm{C}$
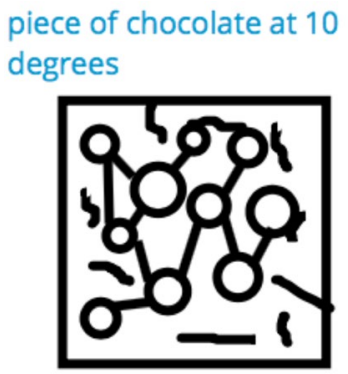

The particles at ten degrees are moving slower than the particles in the chocolate at a higher temperature (the wavy lines represent movement)
Piece of chocolate at 20 degrees

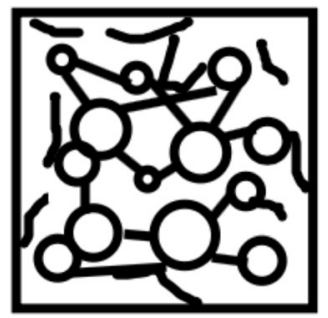

The particles at twenty degrees are moving faster than the particles in the chocolate at a lower temperature 
For the remaining task, where they had to explain thermal energy in ice cream, all three students indicated correctly that there is motion in even a cool solid, indicating their shift in conceptual understanding. Jessica's response showed an awareness of the lowest temperature for matter, and she correctly attributed motion to kinetic energy and related it to thermal energy. Across this sequence of activities, students were able to demonstrate ideas of inter-molecular bonding, along with movement in solids in different contexts, and through multiple modes (e.g., diagrams, role-play, written forms). Their responses in Activities 5.4 and 5.5 indicated growth in conceptual and representational competence.

\section{The coordination of students' representations with scientific ideas}

As part of the pedagogical sequence, students' constructed representations were purposively coordinated with the progressive introduction of scientific ideas to help them gradually move towards scientifically valid representational practices. The scientific ideas were provided through explanations by the teachers as well as through purpose-made videos. As previously mentioned, the first scientific explanation took place in Activity 5.4, after students had explored their conceptions through the previous challenges. Students' responses indicated a shift in their ideas from solid particles as stationary and they were able to represent ideas about motion in both their written text and drawings (see Figs. 4 and 5). In the final activity (Activity 5.5), after watching a second video-based scientific explanation and applying their learning to different contexts, their resultant diagrams or written explanations (see Fig. 6) remained aligned with the accepted scientific view.

In the Convection module, the first video in the module, Energy Transfer by Convection was shown after a brief whole-class discussion (see Activity 7.1). During the animation of water boiling, the teacher briefly paused the video to ask questions about observed phenomena, notably the current and its causes. A student explained: "The warmth is rising up and the cool, the cold is coming down." The remaining video explained convection currents at a particle level and related them to global processes (e.g., weather patterns), along with everyday examples in the house (e.g., heating and cooling) (see Fig. 7).

The video concluded with five key points about convection, which students copied into their project books (see Fig. 8). The teacher then guided students' responses: "I want you to see if you can represent it diagrammatically... potentially using arrows and maybe explaining what is happening here. So... the heat source, what particles are rising to the top? Why are they doing that? Are they more dense? Are they less dense? What's happening to the

Fig. 7 Final screenshots of the video Energy Transfer by Convection (http://www.eeb.ucla. edu/test/faculty/nexlin/Lecture 1/ Fig0803.jpg)

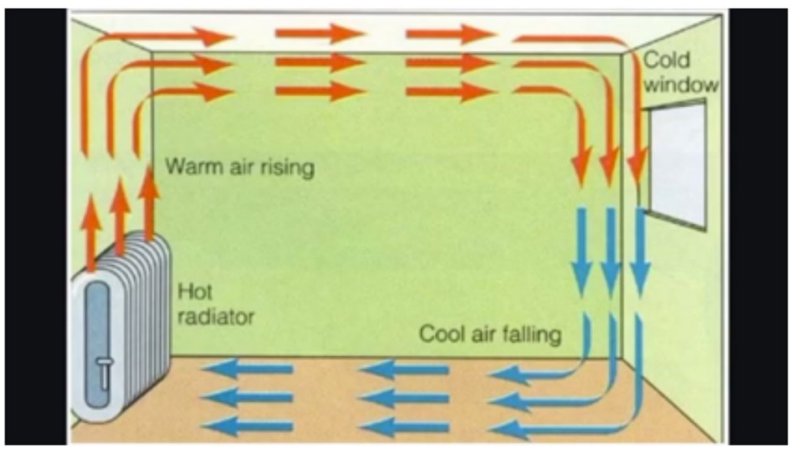




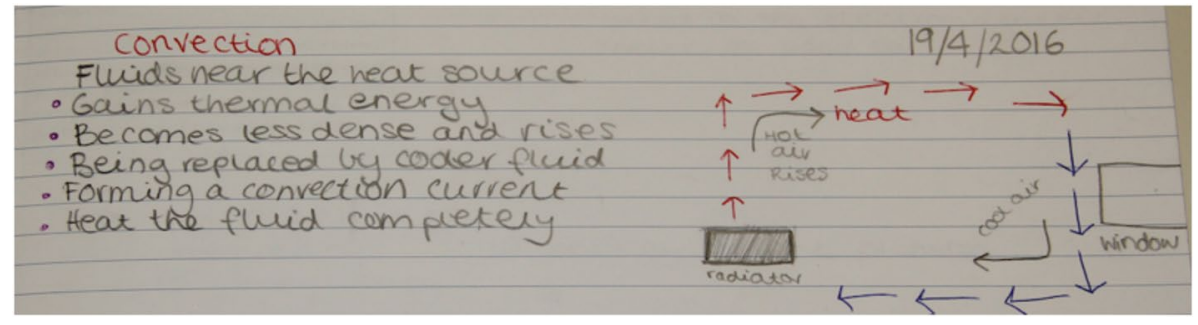

Fig. 8 Jessica's list of the key points and their representations about convection

cooler water?" The case group generated annotated diagrams in their project books (See Jessica's response in Fig. 8).

Like Jessica, the other two students in the case study group also recorded the key points on convection exactly as they appeared in the final slide of the video. Their diagrams resembled the digital representations featured in the video (e.g., position of radiator and window, direction and colour of arrows, annotations), and following the same red-blue arrow convention they correctly indicated the hot air rising and the cool air sinking.

Following the teacher-led demonstration about convection currents, the teacher directed students to respond to related online questions. The first question in this module was textbased and had students explain how a breeze or a fan cools the body. The teacher noticed several students appearing to struggle with this question, so provided an explanation to the whole class, which was later reflected in the case group's responses. Jessica's account was representative of her group: "A breeze helps the convection process, because it moves the hot air away from the body to cool you down".

The remaining two questions were accompanied by an initial image from which students were to construct their responses. Question 2 featured an image of a burning candle, and students were asked to show how the candle flame created a convection current using their knowledge of the particle model and heat energy transfers. To be compatible with scientific ideas, students needed to depict a convection current as the heat energy transfers from the burning flame of the candle to the air, where the hotter or less dense air around the flame rises and is replaced by the cooler or more dense air from below. The case group's responses indicated that they were not able to transfer ideas about convection to this context (see Figs. 9 and 10).

Jessica and McKinley generated similar representations, indicating that both students had adopted the square-shaped convection current, as depicted in the video, without

Fig. 9 Jessica's representations for convection currents around a candle

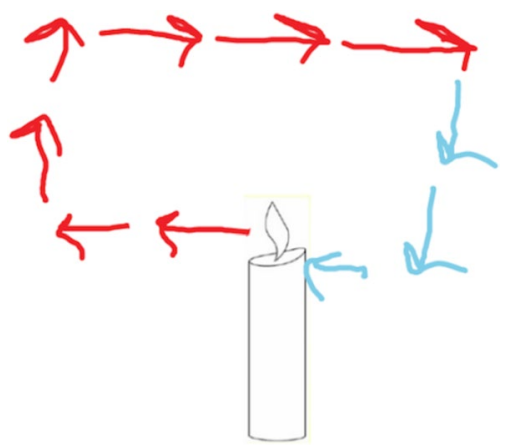


Fig. 10 Clara's representations for convection currents around a candle

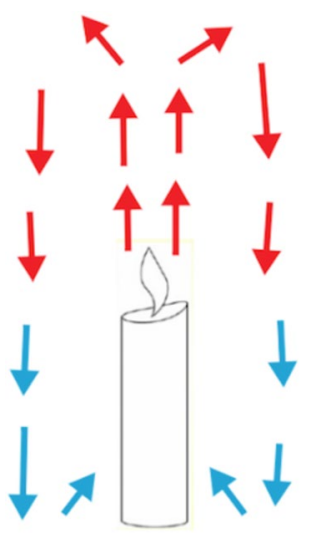

considering spatial arrangement in a different context. Clara's representation was more contextually relevant, but the direction and positioning of the flow of hot and cool currents arrows were not fully consistent with scientific views.

The following question about the convection current in an operating hot water cylinder (Q3) included an image of the hot water system with specific instructions about the colour of arrows (see Appendix 1). To be scientifically accurate, student responses needed to show the cold-water intake on the bottom left and hot water flowing out from the outlet on the top right. All three students followed the red-blue convention prescribed by the question (see McKinley's response in Fig. 11).

However, as with the candle question, all three students tended to apply the representational conventions from the video without adjusting for context, indicating a lack of flexibility in their thinking. None of them correctly addressed all aspects of the question, and McKinley incorrectly indicated cold-water exiting the heater.

\section{Teacher-guided discussion and ongoing evaluation}

In both modules, students addressed all tasks under the direction of the teacher, with most of the activities taking place during classroom time. The first module began with a survey to assess students' prior knowledge (see Activity 5.1 in Appendix 1). The survey tool provided automated feedback, which provided students with detailed conceptual explanations of the given phenomenon based on the alternative conception research (AAAS, 1989). However, students' responses were not shared through whole-class discussions nor used by the teacher to frame following activities. As students undertook the first representational challenge (Activity 5.2), the teacher actively circulated around the classroom, encouraging students to represent each of the scenarios and annotate their drawings. Yet there were no teacher-guided whole class discussions to collaboratively evaluate or refine processes.

During the role play (Activity 5.3), student groups engaged in collaborative reasoning and negotiation as they planned their response. The first author was leading this activity and called on one group to demonstrate (not the case group). This group assembled themselves in a line and, like the case group's response, they stood close but still as 'solid plasticine' in scenario 1. For scenario 2, they then stepped apart with the student on the left initiating side-to-side movement, which the others copied up the line. The first author asked this group to clarify what each student 'represented' and to be specific. Their responses 


\section{Question 3}

The diagram below is a cross-section of a hot water system you might have in your home. It is a tank full of water with a heating element and two openings. When the heating element is turned on hot water will flow out of the system and cold water flow in. Using your understanding of

convection indicate with RED coloured arrows the direction the hot water takes and indicate with BLUE coloured arrows the direction the cold water takes.

Indicate which should be the hot water outlet and why.

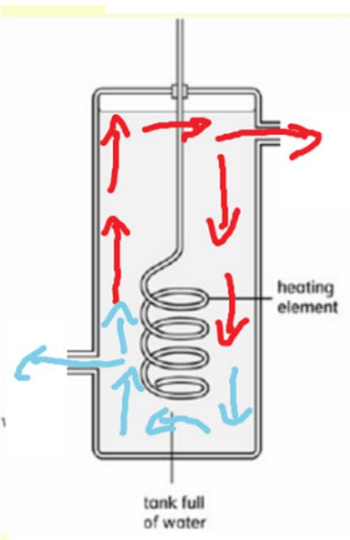

Fig. 11 McKinley's representation of convection currents in a hot water system

included 'plasticine' and 'solid particles'. Though the first author clarified the representation, she did not identify or clarify the common alternative misconception related to their positions as molecules in a solid with the students. Similarly, in Activities 5.4 and 5.5, the teacher provided feedback to each group, but there was no targeted discussion between students or as whole-class around featured representations and possible alternate conceptions.

For the Convection module, the lesson began with a whole-class teacher-led discussion, which was not included in the initial design. The discussion topic was about home heating and cooling systems, and how convection currents of warm and cool air related to an everyday context. The students responded with verbal accounts from their own experiences. For Activity 7.2, though the teacher prompted students to think about how they would draw the teabag rocket and provided guidance about the task, she did not facilitate whole-class collaborative discussions or evaluation around students' representations.

\section{Discussion}

This section discusses the findings in relation to the two research questions concerning the affordances and/or constraints of the STILE online learning platform for facilitating the central learning processes of the RCA and the key considerations that emerge for designing and delivering representation-focused learning sequences online.

In addressing the potential of an online learning platform to facilitate the central learning processes of the RCA, the analysis of students' responses indicated both generative and problematic features in the design and implementation of this online unit. In the first instance, students generated a variety of unique representations, similar in quality and 
variety to those produced with non-digital RCA approaches (e.g., Waldrip et al., 2013). Students' responses demonstrated how the platform's provision of both digital and nondigital representation-focused resources and activities enabled their active engagement in meaning-making processes through cross-modal translation. However, there were issues with the design and delivery of the learning unit that impacted students' ability to understand and generate representations. These included the sequencing of the scientific representations, and the relative absence of teacher-guided dialogue and evaluative feedback. These considerations have implications both for the design of online representational approaches and for associated professional learning programmes, which will be discussed later. The findings in relation to the areas identified in the analytical framework are now examined in more detail.

\section{Constructing and coordinating representations}

By scaffolding students' construction and coordination of representations, the design of the unit in the STILE learning platform went beyond just the delivery of content and enabled students to engage in several semiotic processes including expression and linkage of ideas (via representations), reflection, translation, and refinement of ideas. The platform supported these processes by facilitating access to multiple media and multimodal representational resources in ways not readily available in face-to-face modes.

First, the platform was successful in enabling students to express their ideas through digital or non-digital media (e.g., interactive canvas, project book), with both providing similar drawing affordances (e.g., shape, colour, text) and equivalent quality. In response, students generated a variety of imaginative representations in both modules (Figs. 1, 2, $4,5,6,8)$ that demonstrated their representational competence in depicting both iconic and abstract ideas, consistent with the literature (diSessa, 2004; Kozma \& Russell, 2005). The first drawing-task (Activity 5.2) illustrated how the paint tool allowed the imaginative but critically focused representational work that is central to the RCA's representational challenge. Students' drawings clearly depicted their conceptions of the sub-microscopic arrangements and bonding that a teacher could potentially work with to productively refine their ideas.

In addition, the platform also enabled expansive text-based responses, and so made it possible for students to reflect on their ideas more extensively (Activity 5.3). In addition to textual and visual modes, students were also able to express ideas through an actional mode such as a role-play (Activity 5.3) and another hands-on activity (Activity 7.2), where both activities were scaffolded online but implemented as face-to-face activities. This facility suggested the possibility within the platform for a blended learning environment, which involves the teacher orchestrating activities asynchronously.

Though embedding activities and resources in an online learning sequence might imply fixed pathways, the platform also promoted students' flexibility and agency in accessing representational resources for meaning-making activities. Students constructed their unique learning pathways in response to the sequencing of individual and social learning activities across face-to-face and online environments as a coordinated learning experience. They participated in individual tasks throughout the unit (e.g., surveys, generating representations) and engaged in group (e.g., role-plays, hands-on activities) and whole-class activities (e.g., discussions, demonstrations) that facilitated the social aspects of learning fundamental to RCA and other inquiry approaches. Their distinctive learning journeys were consistent with online inquiry approaches to learning school science (Longo, 2016). For 
example, the WISE platform supports a customisable inquiry map to track students' patterns of learning, along with prompts to guide their explorations and encourage metacognition (e.g., monitoring, predicting) and knowledge integration (e.g., critiquing, interpreting, explaining) (Slotta \& Linn, 2009). The STILE platform in this study supported similar experiences. Further, students' learning journeys were consistent with face-to-face RCA classrooms where student pathways are individual and complex, and require flexible construction with multiple conceptual pathways to understanding (Airey \& Linder, 2009; Tytler \& Prain, 2010).

Both modules also featured purpose-made videos (designed and produced by the third author) that integrated macroscopic and sub-microscopic processes of the particle model to link iconic and abstract representations in context (Johnstone, 1991). Further, the videos illustrated static and dynamic representations, demonstrating how they relate and complement different aspects of a concept to facilitate deeper understanding (Ainsworth, 2006). The embedded questions following the videos in both modules provided an interplay between the expert and student representations, which supported students' integration of scientific information as they refined their representations (Figs. 3 and 7). From a semiotic perspective, this strategic linking of material phenomena with representational systems succinctly demonstrated the translation across modes and suggests digital possibilities as an instructional tool for digital RCA.

\section{Student growth in representational competence and conceptual understanding}

From a socio-semiotic perspective, quality learning is associated with an ability to move flexibly between representational modes when developing explanations of phenomena (Bezemer \& Kress, 2016; Lemke, 2004; Waldrip et al., 2010). Thus, supporting such learning involves opportunities and support for students to translate and refine their ideas across multiple multimodal representations for different contexts.

Both modules demonstrated effective online sequencing of interactions between student generated and scientific resources. For example, the online sequencing in the Temperature module featured the initial elicitation of students' prior ideas through a survey followed by students' gradual uptake and understanding of purpose-built resources and refinement of their ideas over time. In this module the STILE online platform facilitated the central learning processes of RCA because: the online survey allowed customised feedback links to students' individual responses; the interactive canvas enabled open-ended responses that accommodated multi-modal responses (e.g., texts, diagrams); and the platform allowed integration of customised videos as well as links to those publicly available online. The authors were able to carefully scaffold representational challenges within STILE to facilitate students' translation and gradual development of scientific ideas through an ensemble of modes (Kress, 2010), like the first drawing task (Activity 5.2) where the purpose was to expand students' ideas about particle arrangements and inter-particle bonding in relation to macroscopic properties. The affordance of the drawing mode in Activity 5.2 relates to the 'productive constraint' it offers by focusing attention on spatial arrangements and interactions of sub-microscopic elements (Ainsworth, 2006; Tang et al., 2019).

Activities within the platform were also designed as face-to-face modal interactions, including a role-play (Activity 5.3) and the practical activity (Activity 7.2). The use of the actional mode in these activities presented distinct modal affordances by providing a more direct and possibly more powerful link to abstract ideas (Goldin-Meadows, 2016). The role-play (Activity 5.3) presented visuo-spatial affordances that elicited specific 
information about students' persistent alternative conceptions (e.g., there is no molecular movement in solid particles) through their physical demonstration and subsequent reflections. The modal affordance of the role-play lay in the specificity of the spatial relation between students' bodies, their degree of connectedness, and decision-making regarding physical movement, which all provided insight into the case group's understanding of particle motion. The following activity (5.4) involved an interplay between expert and student representations as students re-represented their ideas in a drawing after viewing a short video animation. Students' responses indicated a learning gain related to the movement of particles in a solid, which they were then able to correctly translate into other contexts (Activity 5.5), and across modes-in contrast to their ideas expressed across the multiple modes in Activities 5.1-5.3.

The second example of an actional mode that took place outside the platform was the Teabag Rocket Activity. Like the role-play activity, translating observations to drawing a 2D static image involves the productive constraint (Ainsworth, 2006) since there is the need to explicitly represent spatial relations and movement (Bezemer \& Kress, 2016; Tang et al., 2019). Interestingly, this activity did illustrate a generative cross-modal translation through the mapping task (Fig. 2), which provided a strong conceptual focus that is often missing in practical investigations (Abrahams \& Millar, 2008). Though these generative learning activities took place in a face-to-face delivery mode, they can be included in blended learning delivery. Possibilities for fully online delivery could involve digital simulations or appropriate home-based practical activities (Caruana et al., 2020).

\section{The coordination of students' representations with scientific ideas}

These modules demonstrated the use of embedded sequences of representational challenges, as featured in the RCA, and how their design can support the complex and responsive role of the teacher in framing the tasks, directing attention, responding to the variety of student representations and orchestrating convergence. For example, in the Temperature module, students interacted with the first video only after engaging in a series of embedded open-ended and exploratory multimodal activities, which elicited their prior knowledge. The following activities indicated students' steady uptake of the scientific ideas across different modes (Activities 5.2, 5.3), and their ability to apply the ideas in different contexts (Activities 5.4, 5.5). For example, in Activity 5.4, students demonstrated a productive learning response by refining their representations, instead of merely copying animations from the video, in ways that indicated growth in their understanding of the particle basis of temperature and states of matter. In contrast, for the Convection module, students only engaged in a brief discussion prior to viewing the embedded video (Activity 7.1). The rationale for placing this video early in the sequence was to provide key representational resources (i.e., convection arrows) as the basis for further challenges. However, the scientific ideas in the video seemed to dictate and limit the students' representations in relation to the heat sources or geometry of the context (Figs. 8, 9, 10). Moreover, some of the openended questions included images or prescribed the use of arrows in a way that seemed to constrain students' responses in different contexts (Figs. 9, 10, 11). It appears grappling with the representational problem before being introduced to scientific ideas better prepared students for generative uptake, whereas the early imposition of the convection flow representation in the second module, while a straightforward suggestion on the surface, seemed to lock students into a procedural interpretation that was extended inappropriately to other contexts. 
Timing the introduction of scientific information in any teaching sequence (e.g., textbooks, teachers' explanations) has been identified as a key pedagogical issue in other studies of representation-focused approaches (Lehrer et al., 2000; Tytler et al., 2013). The timing requires balance between allowing students to explore and represent their own ideas about phenomena and providing scientific information and guidance. In a case study with primary students, Lehrer et al. (2000) found that if scientific resources were presented too early, students became more concerned with external features, syntax, or procedure, instead of the meaning; if presented too late, students may not have understood the principles well enough to translate them to another activity. In representation-focused approaches, the time needed to develop personally meaningful learning through students' active construction, revising, evaluating, and problem solving is seen as an investment in developing deeper conceptual understanding that is rarely achieved with transmissive approaches. Consistent with RCA, the findings in this study suggest that careful planning of online units to embed multimodal formative representation-focused activities early in the learning sequence open up insights into students' reasoning and prepares them for engagement in further representational work. Teachers could then refine the planned sequence in response to students' understanding (Kenny \& Cirkony, 2018a, b).

Though the timing of scientific information and resources in the teaching and learning sequence is typically orchestrated by teachers in face-to-face classroom, there have been advances in adaptive learning, which involves the use of automated, dynamic, and interactive content (Kerr, 2016). For example, She and Liao's (2010) web-based adaptive learning system supported ongoing adjustments to students' learning of science based on their current conceptual understanding and reasoning. Recent developments in general instructional models enable automated adaptations of the pacing, sequencing, and format of instructions based on the content and learner responses (Martin \& Markant, 2019). For the approach in this study, the use of the relatively simple show/hide feature within the STILE platform could allow for teacher control over the timely introduction of scientific resources.

\section{Teacher-guided discussion and ongoing evaluation}

Although the authoring tool facilitated the online sequencing of the modules, the delivery required the teacher's ongoing orchestration and adaption of activities to guide students' learning. The findings showed that while the teacher introduced and directed activities, and provided advice around constructing representations, there was limited teacher-guidance and evaluation of students' responses - either as whole-class or student-student discussions. This limited interaction with students resulted in missed opportunities for: the teacher to identify and address possible alternative conceptions and facilitate conceptual growth; and students to clarify form, function, and adequacy of their representations.

Assessing student understanding from their representations is proving to be a problematic area and is gaining increasing attention in the research. Numerous researchers are developing frameworks to address these issues (Tang et al., 2019; Wilson \& Bradbury, 2021; Xu et al., 2021). However, the frameworks are largely concerned with drawing as a mode for delivery and do not address other modes of representation. As a more widely applicable tool, Cirkony \& Kenny (in review) have proposed an assessment rubric as a prompt for teachers, which they claim is easily adaptable to different topic areas and facilitates teachers conducting formative, interactive discussions. The need for such a tool is highlighted and supported by findings from this current study, which indicate the design of a digital RCA requires a more explicit focus on these crucial dialogical interactions around 
representations, such as embedded digital scaffolds or prompts for the teacher. These should focus on the form and function, purpose, and adequacy of students' representations (Tytler et al., 2013; Waldrip et al., 2010; Wilson \& Bradbury, 2021). Other supports might include embedding questions and examples of concept-specific interactions onto the platform (e.g., videos, transcripts).

There are also a number of generative examples of templates or scripts that have been embedded into an online learning environment to facilitate science learning (Martin et al., 2020). For example, in a systematic review, Noroozi et al. (2012) reported that online learning environments lend themselves to constructing and sharing arguments, and that they should be designed systematically to consider specific conditions for learning. Weinberger et al. (2010) demonstrated that computer-supported scripts can specify, sequence, and assign roles to learners that enable both students' collaboration and scientific argumentation. Designing scripts for RCA requires specific guidance around student's representations, as students explain phenomena, make claims and negotiate meaning (e.g., Waldrip et al., 2010). However, such script design requires careful consideration, given the formative and dialogic nature of RCA generates artefacts that are difficult to capture in time and in context (Sellings, 2018; Tytler et al., 2013).

In addition, the capability of the platform to automatically collate open-ended responses would be helpful for teacher-guided interactions with students. In its current form, the STILE platform had the capacity to collect students' digital and uploaded responses for each question as a repository of their learning. However, there was no simple way to aggregate students' responses to individual challenges or questions, which would help the teacher to track and support refinement of students' representations. The development of an automatic aggregation tool for students' open-ended responses would enable the teachers to compare responses for consensus-building discussion and formative assessment purposes, through whole-class negotiation as well as individual reflection.

\section{Online design and delivery}

In addressing the second research question, concerning considerations for designing and delivering representation-focused learning sequences online, the findings highlighted the following three considerations:

\section{The timing of scientific resources}

The STILE online platform provided an expanded set of digital representational-focused resources (e.g., videos, simulation), which built on the traditional emphasis seen in text and diagrams. However, these require careful sequencing to allow RCA processes to be responsive to students' developing understanding and gradual uptake of scientific ideas. While an initial online design may embed such resources after prior knowledge elicitation activities, inclusion of platform features such as the show/hide function would allow for real-time teacher control over the timing of scientific resources based on students' responses.

\section{Cross-modal translations}

The online platform demonstrated opportunities for students to express, re-represent, and refine their ideas through cross-modal representations, including contextual multimodal representational challenges, a role-play, and a mapping task to support hands-on 
experiences. Importantly, the initial activities need to involve the elicitation of students' prior ideas through both closed- and open-ended questions and multimodal activities based around key concepts and common alternative conceptions. Such multimodal activities could include digital surveys, teacher-guided discussions, open-ended responses through text and diagram, and role-plays.

\section{Teacher-guided discussion and evaluation}

Though the teachers introduced and directed activities in this study, there were limited discussions about and evaluation of students' representations. These activities are central to RCA and the teacher has an important role in scaffolding group and whole-class discussions around the form and function, purpose, and adequacy of students' representations, to develop communal understanding. Given that teachers have found this challenging in face-to-face settings (Tytler \& Prain, 2010), the online platform should include embedded supports (e.g., questions, prompts, video illustrations) that explicitly focus on these crucial dialogical interactions around representations. Beyond the platform's capacity to collect students' digital and uploaded responses for each question as a repository of their learning, an automated aggregation tool for students' responses would better enable the teacher to compare for consensus-building discussion and formative assessment purposes.

\section{Conclusion}

This case analysis of the application of RCA through an online platform indicates clear promise for such digital technologies to facilitate active meaning-making processes that effectively emulate multimodal disciplinary knowledge construction processes. This exploratory case study, although restricted in scope, has provided insights into the learning processes revealed through the staged development of students' semiotic resources. These findings, concerning both the affordances and constraints around the online processes, have the potential to inform future studies in this growing research area, particularly considering the increased demand for high-quality online learning experiences. Further, the case study gives clear promise for the adaptation of RCA to an online platform and indicates the need for more research using other platforms.

The platform enabled the sequencing of this interactive pedagogy such that it embraced and expanded a range of generative practices, like that achieved in face-to-face settings. However, the dual task of navigating a complex pedagogy along with interactive online learning platform presented additional demands on both the teacher and students, indicating a need for specific pedagogical supports. With such supports, including careful consideration for the teacher-led delivery and the design and sequencing of online of the activities, the use of such an online learning platform can provide a viable and generative digital approach to representationally rich and effective learning sequences for school-based science education. 


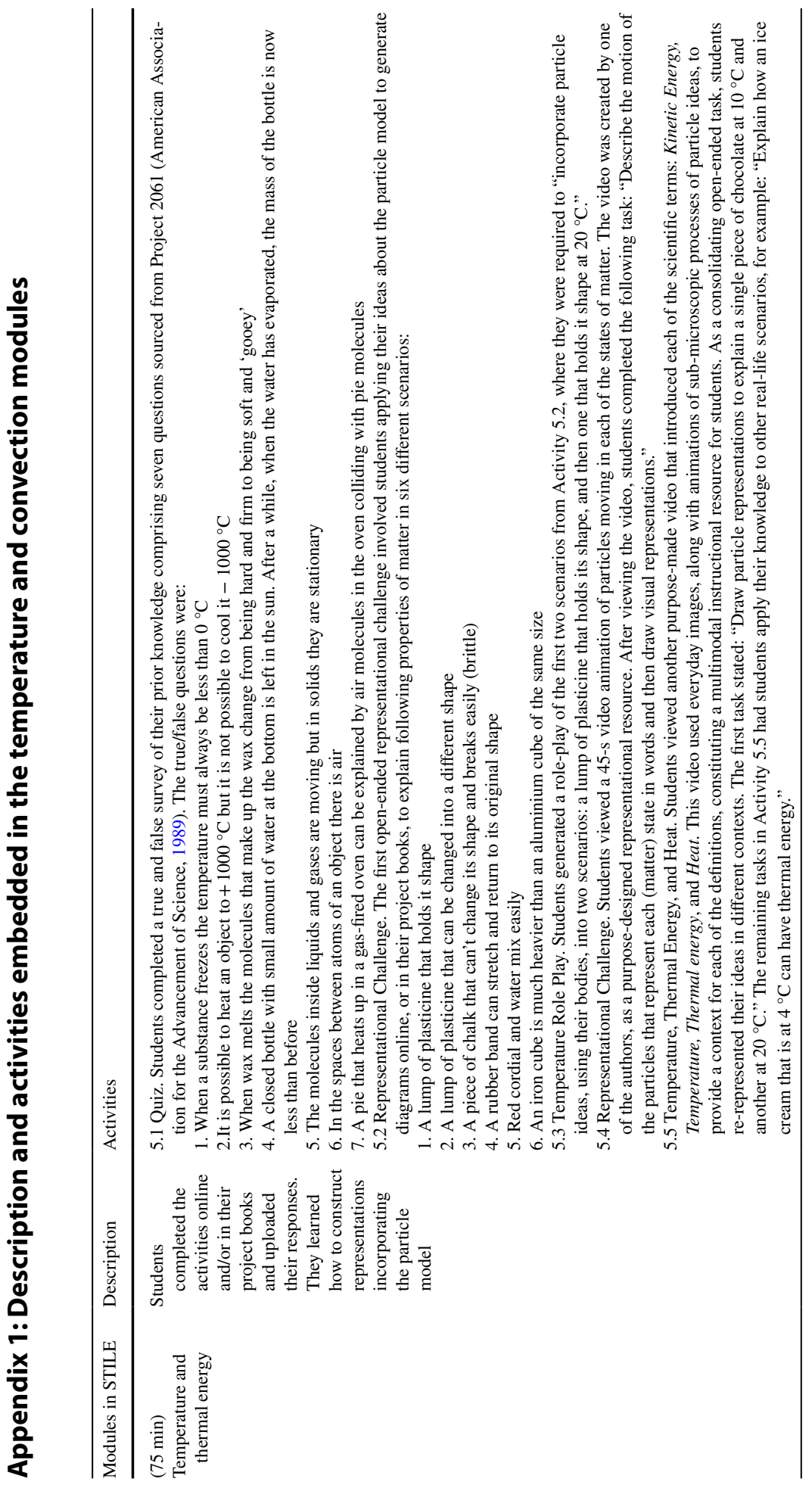




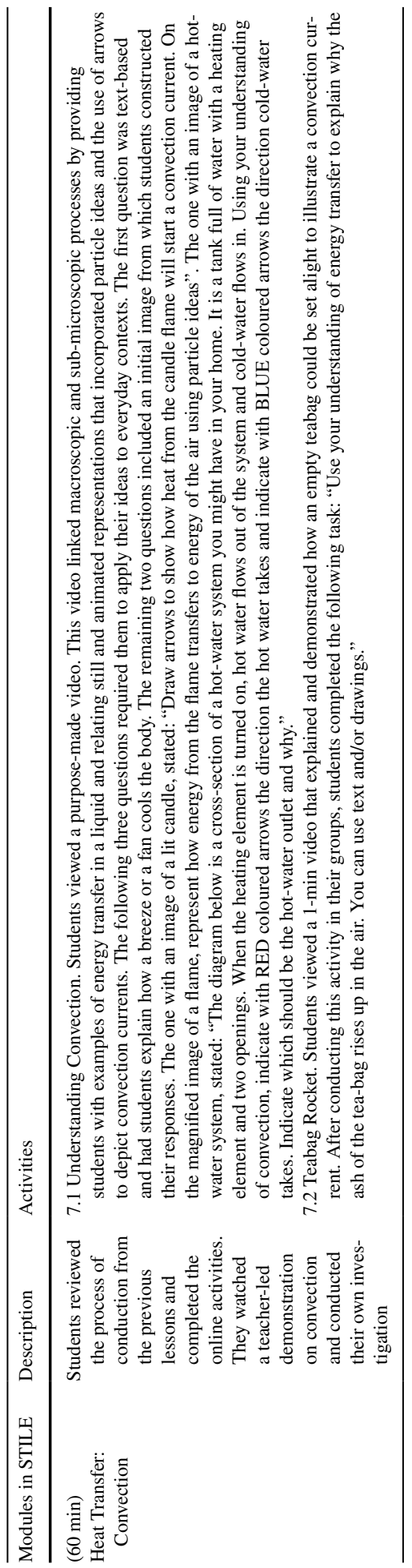


Acknowledgements We wish to acknowledge the Deakin Faculty of Arts and Education and their generous support through a post-graduate publication award. We also wish to acknowledge Dr Anne Hume, from the University of Waikato Faculty of Education, and Emeritus Professor Richard Gundstone, from the Monash University Faculty of Education, for the preparation of this manuscript.

Funding Open Access funding enabled and organized by CAUL and its Member Institutions. This research was supported by the Australian Research Council as part of the Digital Pedagogies project (LP130100233).

\section{Declarations}

Conflict of interest No potential conflict of interest was reported by the authors.

Open Access This article is licensed under a Creative Commons Attribution 4.0 International License, which permits use, sharing, adaptation, distribution and reproduction in any medium or format, as long as you give appropriate credit to the original author(s) and the source, provide a link to the Creative Commons licence, and indicate if changes were made. The images or other third party material in this article are included in the article's Creative Commons licence, unless indicated otherwise in a credit line to the material. If material is not included in the article's Creative Commons licence and your intended use is not permitted by statutory regulation or exceeds the permitted use, you will need to obtain permission directly from the copyright holder. To view a copy of this licence, visit http://creativecommons.org/licenses/by/4.0/.

\section{References}

Abrahams, I., \& Millar, R. (2008). Does practical work really work? A study of the effectiveness of practical work as a teaching and learning method in school science. International Journal of Science Education, 30(14), 1945-1969. https://doi.org/10.1080/09500690701749305

Ainsworth, S. (2006). DeFT: A conceptual framework for considering learning with multiple representations. Learning and Instruction, 16(3), 183-198.

Ainsworth, S., Prain, V., \& Tytler, R. (2011). Drawing to learn in science. Science, 333, 1096-1097.

Airey, J., \& Linder, C. (2009). A disciplinary discourse perspective on university science learning: Achieving fluency in a critical constellation of modes. Journal of Research in Science Teaching: THe Official Journal of the National Association for Research in Science Teaching, 46(1), 27-49.

American Association for the Advancement of Science. (1989). Science for all Americans: A project 2061 report on literacy goals in science, mathematics and technology. Retrieved from http://www.proje ct2061.org/publications/sfaa/online/sfaatoc.htm. Accessed on December 9, 2021

An, Y., Kaplan-Rakowski, R., Yang, J., Conan, J., Kinard, W., \& Daughrity, L. (2021). Examining K-12 teachers' feelings, experiences, and perspectives regarding online teaching during the early stage of the COVID-19 pandemic. Educational Technology Research and Development. https://doi.org/10.1007/ s11423-021-10008-5

Australian Curriculum, Assessment and Reporting Authority. (2018). Curriculum content descriptions (ACSSU182). Retrieved from http://www.scootle.edu.au/ec/search?accContentId=ACSSU182

Barbour, M. K. (2014). A history of international K-12 online and blended instruction. In R. Ferdig \& K. Kennedy (Eds.), Handbook of research on $\mathrm{K}-12$ online and blended learning (pp. 25-50). Entertainment Technology Center Press.

Bezemer, J., \& Kress, G. (2016). Multimodality, learning and communication. A social semiotic frame. Routledge.

Caruana, D. J., Salzmann, C. G., \& Sella, A. (2020). Practical science at home in a pandemic world. Nature Chemistry, 12, 780-783. https://doi.org/10.1038/s41557-020-0543-z

Cirkony, C. (2019). Students learning science: Representation construction in a digital environment. (Doctoral thesis). Deakin University, Australia

Cohen, L., Manion, L., \& Morrison, K. (2013). The ethics of educational and social research. Research methods in education (pp. 99-128). Routledge.

Daniel, K., Bucklin, C., Leone, E., \& Idema, J. (2018). Towards a definition of representational competence. In K. Daniel (Ed.), Towards a framework for representational competence in science education (pp. 3-11). Springer. https://doi.org/10.1007/978-3-319-89945-9

diSessa, A. A. (2004). Metarepresentation: Native competence and targets for instruction. Cognition and Instruction, 22(3), 293-331. 
diSessa, A. A., \& Sherin, B. L. (2000). Meta-representation: An introduction. The Journal of Mathematical Behavior, 19(4), 385-398.

Flyvbjerg, B. (2006). Five misunderstandings about case-study research. Qualitative Inquiry, 12(2), 219245. https://doi.org/10.1177/1077800405284363

Freeman, A., Adams Becker, S., Cummins, M., Davis, A., \& Hall Giesinger, C. (2017). NMC/CoSN Horizon Report: 2017 K-12 Edition. Austin, TX: The New Media Consortium. Retrieved from https://cdn.nmc. org/media/2017-nmc-cosn-horizon-report-k12-EN.pdf. Accessed on December 9, 2021

Furberg, A., Kluge, A., \& Ludvigsen, S. (2013). Student sensemaking with science diagrams in a computerbased setting. International Journal of Computer-Supported Collaborative Learning, 8(1), 41-64. https://doi.org/10.1007/s11412-013-9165-4

Goldin-Meadows, S. (2016). Using our hands to change our minds. Wires Cognitive Science. https://doi.org/ $10.1002 /$ wcs. 1368

Gibson, J. J. (1979). The theory of affordances: The ecological approach to visualperception (pp. 127-143). Boston, MA: Houghton Miffin.

Hollamby, P. (2006). Particles in Motion. Royal Society of Chemistry and Science Enhancement Programme [CD-ROM]. Royal Society of Chemistry.

Hubber, P., Tytler, R., \& Haslam, F. (2010). Teaching and learning about force with a representational focus: Pedagogy and teacher change. Research in Science Education, 40(1), 5-28. https://doi.org/10.1007/ s11165-009-9154-9

Johnstone, A. H. (1991). Why is science difficult to learn? Things are seldom what they seem. Journal of Computer Assisted Learning, 7(2), 75-83.

Jupp, V. (2006). The SAGE dictionary of social research methods. SAGE.

Kenny, J. \& Cirkony, C. (in review). Exploring assessment to address the impact of educational policy on classrooms: using inquiry in science as an exemplar

Kenny, J., \& Cirkony, C. (2018a). Teaching using student-generated representations (SGRs) in science. In G. Woolcott \& R. Whannell (Eds.), Science teaching theory and practice: Engaging with scientific thinking, problem solving and real world contexts (pp. 141-67). Cambridge, UK: Cambridge University Press.

Kenny, J., \& Cirkony, C. (2018b). Using representations in the science classroom. In G. Woolcott \& R. Whannell (Eds.), Science teaching theory and practice: Engaging with scientific thinking, problem solving and real world contexts (pp. 348-74). Cambridge, UK: Cambridge University Press.

Kerr, P. (2016). Adaptive learning. Elt Journal, 70(1), 88-93. https://doi.org/10.1093/elt/ccv055

Klette, K. (2009). Challenges in strategies for complexity reduction in video studies. Experiences from the PISA+ study: A video study of teaching and learning in Norway. In T. Janik \& T. Seidel (Eds.), The power of video studies when investigation teaching and learning in classrooms (pp. 61-83). Waxmann.

Knain, E., Fredlund, T., \& Furberg, A. (2021). Student reasoning and representation construction in school science through the lenses of social semiotics and interaction analysis. Research in Science Education, 51, 93-111. https://doi.org/10.1007/s11165-020-09975-1

Kozma, R., \& Russell, J. (2005). Students becoming chemists: Developing representational competence. In J. Gilbert (Ed.), Visualization in science education (pp. 121-146). Springer.

Kress, G. (2010). Multimodality: A social semiotic approach to contemporary communication. Routledge.

Latour, B. (1990). Drawing things together. In M. Lynch \& S. Woolgar (Eds.), Representations in scientific practice (pp. 19-68). Kluwer Academic Publishers.

Lehrer, R., \& Schauble, L. (2006). Cultivating model-based reasoning in science education. In R. K. Sawyer (Ed.), Cambridge handbook of the learning sciences (pp. 371-387). Cambridge University Press.

Lehrer, R., Schauble, L., Carpenter, S., \& Penner, D. (2000). The interrelated development of inscriptions and conceptual understanding. In P. Cobb, E. Yackel, \& K. McCain (Eds.), Symbolizing and communicating in mathematics classrooms. Perspectives on discourse, tools and instructional design (pp. 325-360). Lawrence Erlbaum Associates.

Lemke, J. (1998). Multiplying meaning: Visual and verbal semiotics in scientific text. In J. Martin \& R. Veel (Eds.), Reading science (pp. 87-113). Routledge.

Lemke, J. (2004). The literacies of science. In E. W. Saul (Ed.), Crossing borders in literacy and science instruction: Perspectives on theory and practice (pp. 33-47). International Reading Association.

Longo, C. (2016). Changing the instructional model: Utilizing blended learning as a tool of inquiry instruction in middle school science. Middle School Journal, 47(3), 33-40. https://doi.org/10.1080/00940771. 2016.1135098

Means, B., Toyama, Y., Murphy, R., Bakia, M., \& Jones, K. (2009). Evaluation of evidence-based practices in online learning: A meta-analysis and review of online learning studies. Washington, DC: US Department of Education, Office of Planning, Evaluation, and Policy Development. 
Martin, F., Chen, Y., Moore, R. L., \& Westine, C. (2020). Systematic review of adaptive learning research designs, context, strategies, and technologies from 2009 to 2018. Educational Technology Research and Development, 68, 1903-1929. https://doi.org/10.1007/s11423-020-09793-2

Martin, F., \& Markant, D. (2019). Adaptive learning modules. In M. E. David \& M. J. Amey (Eds.), The SAGE encyclopedia of higher education. Sage.

Noroozi, O., Weinberger, A., Biemans, H. J. A., Mulder, M., \& Chizari, M. (2012). Argumentation based computer supported collaborative learning (ABCSCL). A systematic review and synthesis of fifteen years of research. Educational Research Review, 7, 79-106.

Panjaburee, P., \& Srisawasdi, N. (2016). An integrated learning styles and scientific investigation-based personalized web approach: A result on conceptual learning achievements and perceptions of high school students. Journal of Computers in Education, 3(3), 253-272. https://doi.org/10.1007/ s40692-016-0066-1

Peirce, C. S. (1998). The essential Peirce: Selected philosophical writings. Indiana University Press.

Pink, S. (2007). Doing visual ethnography: Images, media and representation in research. Retrieved from 395 http://ezproxy.deakin.edu.au/login?url=http://SRMO.sagepub.com/view/doing-visual-ethnography/SAGE.xml. Accessed on December 9, 2021

Prain, V., \& Tytler, R. (2012). Learning through constructing representations in science: A framework of representational construction affordances. International Journal of Science Education, 34(17), 27512773. https://doi.org/10.1080/09500693.2011.626462

Richards, J., \& Dede, C. (2012). Introduction: Opportunities and challenges of digital teaching platforms. In C. Dede \& J. Richards (Eds.), Digital teaching platforms (pp. 1-6). Teachers College Press.

Sellings, P. (2018). Assessing student-generated representations to explore theory-practice connections. In M. Barnes, M. Gindidis, \& S. Phillipson (Eds.), Evidence-based learning and teaching: A look into Australian classrooms (Ch. 10). New York, NY: Routledge.

She, H. C., \& Liao, Y. W. (2010). Bridging scientific reasoning and conceptual change through adaptive web-based learning. Journal of Research in Science Teaching, 47(1), 91-119. https://doi.org/10.1002/ tea. 20309

Slotta, J., \& Linn, M. (2009). WISE Science: Web-based inquiry in the classroom. New York, NY: Teachers College Press.

Taber, K. (2013). Modelling learners and learning in science education. Springer.

Tang, K. S., \& Danielsson, K. (Eds.). (2018). Global developments in literacy research for science education. Springer International Publishing.

Tang, K., Won, M., \& Treagust, D. (2019). Analytical framework for student-generated drawings. International Journal of Science Education, 41(16), 2296-2322. https://doi.org/10.1080/09500693.2019. 1672906

Tytler, R., Hubber, P., Prain, V., \& Waldrip, B. (2013). Constructing representations to learn in science. Sense Publishers.

Tytler, R., \& Prain, V. (2010). A framework for re-thinking learning in science from recent cognitive science perspectives. International Journal of Science Education, 32(15), 2055-2078. https://doi.org/10.1080/ 09500690903334849

Victoria Deparment of Education (2020). Stile Science-DET Login. https://fuse.education.vic.gov.au/Resou rcePackage/LandingPage?objectId=0945c003-c030-4b58-a2d4-b49a4ffe59c6\&SearchScope=Teacher. Accessed on December 9, 2021

Waldrip, B., Prain, V., \& Carolan, J. (2010). Using multi-modal representations to improve learning in junior secondary science. Research in Science Education, 40(1), 65-80. https://doi.org/10.1007/ s11165-009-9157-6

Waldrip, B., Prain, V., \& Sellings, P. (2013). Explaining Newton's laws of motion: Using student reasoning through representations to develop conceptual understanding. Instructional Science, 41(1), 165-189. https://doi.org/10.1007/s11251-012-9223-8

Weinberger, A., Stegmann, K., \& Fischer, F. (2010). Learning to argue online: Scripted groups surpass individuals (unscripted groups do not). Computers in Human Behavior, 26, 506-515.

Wilson, R. E., \& Bradbury, L. U. (2021). Assessing early primary students' growth in a science unit using multiple modes of representation: Investigating the promise of explicit drawing instruction. International Journal of Science Education. https://doi.org/10.1080/09500693.2021.1909774

Wittrock, M. C. (1992) Generative learning processes of the brain. Educational Psychologist, 27(4), 531541. https://doi.org/10.1207/s15326985ep2704_8

Wu, Y.-T., \& Wang, L.-J. (2016). Research trends in technology-enhanced knowledge building pedagogies: A review of selected empirical research from 2006 to 2015. Journal of Computers in Education, 3(3), 353-375. 
Xu, L., Prain, V., \& Speldewinde, C. (2021). Challenges in designing and assessing student interdisciplinary learning of optics using a representation construction approach. International Journal of Science Education, 43(6), 844-867. https://doi.org/10.1080/09500693.2021.1889070

Yin, R. K. (2014). Case study research: Design and methods. Sage Publishing.

Publisher's Note Springer Nature remains neutral with regard to jurisdictional claims in published maps and institutional affiliations.

Connie Cirkony is a research fellow in the Faculty of Education at Monash University. Her research focus in science education is about improving students learning experiences around contemporary socio-scientific issues in digital learning environments.

Russell Tytler is the Chair in Science Education in the School of Education at Deakin University and a Fellow of the Social Sciences Association of Australia. He has a strong interest in innovation in science teaching and science teacher education, with a particular focus on supporting reasoning in science.

Peter Hubber was formerly an associate professor in Science Education in the School of Education at Deakin University. He has a strong interest in teaching and learning through representations.

\section{Authors and Affiliations}

\section{Connie Cirkony ${ }^{1}$ (D) $\cdot$ Russell Tytler ${ }^{2}$ (D) $\cdot$ Peter Hubber $^{2}$ (D)}

Russell Tytler

russell.tytler@deakin.edu.au

Peter Hubber

hubberpeter54@gmail.com

1 Faculty of Education, Monash University, Melbourne, Australia

2 School of Education, Deakin University, Melbourne, Australia 